\title{
Drug Insight: antiangiogenic therapies for gastrointestinal cancers-focus on monoclonal antibodies
}

\author{
Anke Reinacher-Schick, Michael Pohl and Wolff Schmiegel \\ Nature Clinical Practice Gastroenterology \& Hepatology (2008) 5: 250-267 [doi:10.1038/ncpgasthep1097]
}

\section{CORRIGENDUM}

In the May 2008 issue, in the Review by Reinacher-Schick et al., there was an error in the response rate figures reported for the study by Saltz et al. ${ }^{95}$ in Table 2 on page 257. The correct response rates should be $38 \%$ versus $38 \%$ instead of $46.5 \%$ versus $37.5 \%$ as shown in the corrected Table 2 below. The Saltz et al. paper was available in abstract form only at the time of publication, but has now been published in full; the updated reference details are included below. ${ }^{95}$

\section{Reference}

95 Saltz LB et al. (2008) Bevacizumab in combination with oxaliplatin-based chemotherapy as first-line therapy in metastatic colorectal cancer: randomized phase III study. J Clin Oncol 26: 2013-2019

\section{Published online}

12 August 2008

www.nature.com/clinicalpractice doi:10.1038/ncpgasthep1237

Table 2 Examples of recent trials with the VEGF-specific antibody bevacizumab.

\begin{tabular}{|c|c|c|c|c|c|c|c|c|c|}
\hline Study & Phase & $N^{a}$ & Protocol & $\begin{array}{l}\text { Response } \\
\text { rate (\%) }\end{array}$ & $P$ value & $\begin{array}{l}\text { PFS } \\
\text { (months) }\end{array}$ & $P$ value & $\begin{array}{l}\text { MS } \\
\text { (months) }\end{array}$ & $\begin{array}{l}P \\
\text { value }\end{array}$ \\
\hline \multicolumn{10}{|l|}{ CRC } \\
\hline Hochster et al. (2006) ${ }^{94}$ & II & $\begin{array}{l}147 \\
213\end{array}$ & $\begin{array}{l}\text { FOLFOX/bFOL/CapOx } \\
\text { FOLFOX/bFOL/ } \\
\text { CapOx+Bev }\end{array}$ & $\begin{array}{l}22.0-43.0 \\
41.0-53.0\end{array}$ & $\begin{array}{l}\text { NA } \\
\text { NA }\end{array}$ & $\begin{array}{l}6.1-8.7 \\
8.3-10.3\end{array}$ & $\begin{array}{l}\text { NA } \\
\text { NA }\end{array}$ & $\begin{array}{l}18.2 \\
24.4\end{array}$ & $\begin{array}{l}\text { NA } \\
\text { NA }\end{array}$ \\
\hline Saltz et al. $(2007)^{95}$ & III & $\begin{array}{l}701 \\
699\end{array}$ & $\begin{array}{l}\text { FOLFOX/CapOx } \\
\text { FOLFOX/CapOx+Bev }\end{array}$ & $\begin{array}{l}38 \\
38\end{array}$ & $\begin{array}{l}0.99 \\
\text { NA }\end{array}$ & $\begin{array}{l}8.0 \\
9.4\end{array}$ & $\begin{array}{l}0.002 \\
\text { NA }\end{array}$ & $\begin{array}{l}19.9 \\
21.3\end{array}$ & $\begin{array}{l}0.077 \\
\text { NA }\end{array}$ \\
\hline Kabbinavar et al. (2005) 89 & III & $\begin{array}{l}105 \\
104\end{array}$ & $\begin{array}{l}5 \mathrm{FU} / \mathrm{LV} \\
5 \mathrm{FU} / \mathrm{LV}+\mathrm{Bev}\end{array}$ & $\begin{array}{l}15.0 \\
26.0\end{array}$ & $\begin{array}{l}0.055 \\
\text { NA }\end{array}$ & $\begin{array}{l}5.2 \\
9.2\end{array}$ & $\begin{array}{l}0.0002 \\
\text { NA }\end{array}$ & $\begin{array}{l}12.9 \\
16.6\end{array}$ & $\begin{array}{l}0.16 \\
\text { NA }\end{array}$ \\
\hline \multicolumn{10}{|l|}{ GC } \\
\hline Shah et al. $(2006)^{132}$ & ॥ & 34 & Cisplatin/CPT-11+Bev & 65.0 & NA & 8.3 & NA & 12.3 & NA \\
\hline \multicolumn{10}{|l|}{ HCC } \\
\hline Schwartz et al. (2006) ${ }^{125}$ & ॥ & 30 & Bev & 10.0 & NA & 6.5 & NA & NA & NA \\
\hline Sun et al. $(2007)^{127}$ & II & 32 & $\mathrm{CapOx}+\mathrm{Bev}$ & 13.3 & NA & 5.4 & NA & 10.6 & NA \\
\hline Thomas et al. $(2007)^{128}$ & II & 29 & Erlotinib + Bev & 21.0 & NA & 9.0 & NA & 19.0 & NA \\
\hline
\end{tabular}

